\title{
Prevalence of Depression among Type 2 Diabetic Outpatients in Black Lion General Specialized Hospital, Addis Ababa, Ethiopia
}

\author{
Tesfa Dejenie Habtewold, ${ }^{1}$ Yosef Tsige Radie, ${ }^{2}$ and Nigussie Tadesse Sharew ${ }^{1}$ \\ ${ }^{1}$ Department of Nursing, College of Health Science, Debre Berhan University, Debre Berhan, Ethiopia \\ ${ }^{2}$ Department of Nursing and Midwifery, College of Health Science, Addis Ababa University, Addis Ababa, Ethiopia \\ Correspondence should be addressed to Tesfa Dejenie Habtewold; tesfadej2003@gmail.com
}

Received 19 October 2014; Revised 1 December 2014; Accepted 10 December 2014

Academic Editor: Janusz K. Rybakowski

Copyright (c) 2015 Tesfa Dejenie Habtewold et al. This is an open access article distributed under the Creative Commons Attribution License, which permits unrestricted use, distribution, and reproduction in any medium, provided the original work is properly cited.

\begin{abstract}
Background. The emotional consequences of diabetes have been scrutinized by a number of investigative teams and there are varying reports about the association of depression with type 2 diabetes mellitus. However, there is limited data about this in Ethiopia. Therefore, the purpose of this study was to assess the prevalence of comorbid depression among type 2 diabetic outpatients. Methods and Materials. Institution based cross-sectional study design was conducted on a random sample of 276 type 2 diabetic outpatients from Black Lion General Specialized Hospital. Systematic random sampling technique was used to get these individual patients from 920 type 2 diabetic outpatients who have an appointment during the data collection period. Patients' depression status was measured using Patient Health Questionnaire 9 (PHQ 9). Result. Totally 264 type 2 diabetic outpatients were interviewed with a response rate of $95.6 \%$. The prevalence of depression among type 2 diabetic outpatients was $13 \%$. Based on PHQ 9 score, 28.4\% (75) fulfilled the criteria for mild depression, $12.1 \%$ (32) for moderate depression, $2.7 \%$ (7) for moderately severe depression, and $1.5 \%$ (4) for severe depression. But $45.8 \%$ (121) of patients had no clinically significant depression. Conclusion. This study demonstrated that depression is a common comorbid health problem in type 2 diabetic outpatients with a prevalence rate of $13 \%$.
\end{abstract}

\section{Background}

1.1. Introduction. Diabetes mellitus is a chronic metabolic disease, characterized by a disorder in the metabolism of carbohydrates, lipids, and amino acids, either as a result of decreased insulin secretion or due to a reduction to insulin sensitivity of the cells of the body cells. It is a disease that acquires epidemic form and constitutes one of the major threats to human health in the 21st century [1].

The World Health Organization projected that 300 million people will suffer from diabetes by 2025 [2]. Ethiopia, which is one of the developing nations, is at a risk of increased diabetes incidence. In 2012 the estimated diagnosed diabetes cases (20-79 years) and estimated numbers of people with undiagnosed diabetes (20-79 years) in 1000s in Ethiopia are $1,386.64$ and 1,145.50, respectively. The estimated diabetesrelated death is 23,869 (20-79 years) [3].

The emotional consequences of diabetes have been scrutinized by a number of investigative teams [4]. A growing body of literature has established a strong association between depression and type 2 diabetes [2,4-7]. And the negative impact depression can have on quality of life together with the increased healthcare costs of comorbid depression for people with diabetes have been recognized [7]. Correspondingly surveys and meta-analyses conducted on diabetes mellitus and depression have shown that comorbid depression was common and the existence of diabetes mellitus doubles/triples the probabilities of depression occurrence [616]. Comorbid depression and diabetes may significantly worsen the course of both disorders, leading to increased socioeconomic stress, reduced functioning and quality of life, and higher complication and mortality rates [17]. On the contrary, O'Connor et al. compared diabetic and nondiabetic samples of patients in Great Britain and found no clear relationship between onset of diabetes and depression [18].

1.2. Prevalence of Comorbid Depression. The prevalence of depression has varied tremendously by definition, study design, source of subjects, study area, time frame, and measurement methods in previous studies. Thus, it is difficult 
to accurately estimate the potential medical care needs and public health burdens of depression in the general diabetic population [19]. A number of studies, including systematic review and meta-analyses, have shown the occurrence of depression among type 2 diabetic patients [20].

Studies from USA and UK reported the prevalence of depression in patients with type 2 diabetic patient varying from 30 to $83 \%[19,21]$. In addition, prevalence estimates among Hispanics indicate that diabetes is associated with a twofold higher risk of comorbid depression compared to the general population, with rates as high as 33\% [7]. Similarly a quarterly publication and prevalence study in Mexico stated that $31 \%$ of people with type 2 diabetes report significant depressive symptoms and approximately $11 \%$ meet criteria for a major depressive disorder [14] and $46 \%$ of patients with Type 2 diabetes diagnosed using the Beck Depression Inventory [22], respectively. Acee also found that $31.1 \%$ of older Mexican American diabetics reported clinically significant levels of depressive symptoms [23].

In a study from the European Depression in Diabetes (EDID) research consortium, prevalence rates for depressive affect in outpatients with diabetes ranged between $34 \%$ and $39 \%$ for Croatian, $19 \%$ and $21 \%$ for Dutch, and $19 \%$ and $39 \%$ for English [24].

Other studies conducted in Asian countries also support the above findings from European and American countries. A cross-sectional study conducted in Chandigarh, India, discovered that, from 300 type 2 diabetic patients, 23\% (68) fulfilled the criteria for severe depression, $18 \%$ (54) for moderate depression, and 59\% (178) had no clinically significant depression [2]. Likewise, a cross-sectional study done in Bangladesh using PHQ-9 (score $\geq 5$ ) depicted that the prevalence of depressive symptoms was 34\% (142). When a cut-off value (PHQ-9 $\geq 10$ ) indicative of moderate to severe depression was used, the prevalence was to be $16.5 \%$ (69) which was supportive of the above findings [25].

Besides there are studies, systematic reviews, and metaanalysis which reported similar result. A study done in South Australia [20] and Iran [26] found that the prevalence of depression in patients with type 2 diabetes mellitus was $23.6 \%$ and 55\%, respectively. Another study showed that the rates of elevated depressive symptoms have been found to be $27 \%$ in type 2 diabetes mellitus [8].

Furthermore, several reviews indicate that the prevalence of comorbid major depressive disorder (MDD) in persons with diabetes ranges from 11 to $33 \%$ [13]. Acee reviewed 20 studies of the comorbidity of depression and diabetes and found that the prevalence of current depression in diabetic samples averaged around $15 \%$, much higher than in the general population [23].

In the same way, a meta-analysis by O'Connor et al. identified the prevalence of depression in diabetes ranging from 8 to $61 \%$ [18].

Similar research from Africa also reported comparable finding. A cross-sectional study at Jos University Teaching Hospital, Jos, Nigeria discovered that the prevalence rate of depression among diabetic outpatients was 19.4\% [27].

In Ethiopia mental health has been one of the most disadvantaged health programs, both in terms of facilities and trained manpower. However, during the last decade, encouraging efforts have been taken to expand services throughout the country [28].

However, in spite of the huge impact of comorbid depression and diabetes on the individual and its importance as a public health problem, little is known about the magnitude of depression in people with diabetes in Ethiopia.

\section{Significance of the Study}

Clinical guidelines advise screening for depression in patients with diabetes [5]. A timely identification of patients with subthreshold or clinical depression and a structured approach for the management of depression in diabetes has proved to be effective in reducing the burden of depression in diabetes. In the short term, healthcare expenditure can be saved. In the long term, a better prognosis, maintenance, or improvement in quality of life can be achieved in patients with diabetes, which is the ultimate goal of diabetes therapy [29]. Previous research into the prevalence of depression in diabetes has enhanced our understanding of the magnitude of the problem of depression and its ramifications. But only a few studies have been conducted in specialist diabetes care settings.

Data on depression among diabetes patients in Ethiopia are inadequate particularly for type 2 diabetic outpatients. Therefore, this study will be helpful in extending understanding of the relationship of depression to diabetes thoroughly investigating prevalence of depression in type 2 diabetic outpatients. Additionally, it will help health care providers to initiate early diagnosis and management of depression based on a research finding, and provides policy makers and NGOs with relevant information for future planning and interventions. At last, it will be used as input for further research.

\section{Objective}

To assess the prevalence of comorbid depression among type 2 diabetic outpatients presenting to Black Lion General Specialized Hospital, Addis Ababa.

\section{Methods and Materials}

4.1. Study Area. Black Lion (Tikur Anbessa in Amharic) General Specialized Hospital, located in the nation's capital Addis Ababa, is Ethiopia's largest general public hospital and one of University Hospitals in the country. The hospital provides a tertiary level referral treatment and is open for 24 hours for emergency services. Black Lion General Specialized Hospital offers diagnosis and treatment for approximately 370,000400,000 patients a year [30].

There are different units and clinics that provide specialized service for clients and patients. Among these clinics diabetes clinic was one of the clinics inaugurated by Prof. Dr Giuseppe "Pino" Grimaldi (president of the international association of lions clubs) on Saturday 12th November 1994. In diabetes clinic approximately 115 type 2 diabetic patients were seen weekly. 
4.2. Study Design. Institution based cross-sectional study design was used to assess the prevalence of comorbid depression among patients with type 2 diabetes mellitus.

4.3. Study Period. The study was conducted from September 23, 2013, to May 13, 2013.

4.4. Source Population. All type 2 diabetes outpatients are on follow-up treatment in diabetes clinic.

4.5. Study Population. Type 2 diabetes outpatients have follow-up appointment during data collection period.

4.6. Sample Size Determination. The actual sample size for the study was determined using single population proportion formula:

$$
n_{i}=\frac{(Z(a / 2))^{2} p q}{d^{2}}
$$

where $n_{i}=$ required initial sample size, $Z_{a / 2}=$ critical value for normal distribution at $95 \%$ confidence interval which equals $1.96(Z$ value at alpha $=0.05), P=$ proportion of success; that is, the prevalence of depressive symptoms using the PHQ-9 (score $\geq 5$ ) was $34 \%$ [25], $q=$ proportion of type 2 diabetic population not having comorbid depression (0.66), and $d=$ marginal error (0.05):

$$
n_{i}=\frac{(1.96)^{2} \times 0.34 \times 0.66}{(0.05)^{2}}
$$

$n_{i}=345$.

Since the sampling was made from finite population $(N<$ 10,000), it needs finite population correction. Therefore,

$$
\begin{gathered}
n_{f}=\frac{n_{i}}{1+n_{i} / N}, \\
n_{f}=\frac{345}{1+345 / 920},
\end{gathered}
$$

where $n_{f}$ was the final sample size, $n_{i}$ was the initial sample size determined using the formula, and $N$ was the size of the source population. By considering $10 \%$ nonresponse rate, the total sample size was 276 type 2 diabetic outpatients.

4.7. Sampling Procedure. As illustrated in Figure 1, these 276 samples were selected by using systematic random sampling technique. The individual type 2 diabetic outpatient was approached through calculating sampling interval $K(N / n$, where $N$ is the total number of type 2 diabetic patients who have appointment during the data collection period which was approximately 920 and $n$ was the calculated final sample size which was 276):

$$
\begin{aligned}
& K=920 / 276 ; \\
& K=3.3 \approx 3 .
\end{aligned}
$$

So that the individual type 2 diabetic outpatient was interviewed every $K$ th; that is, every 3 rd patient was selected

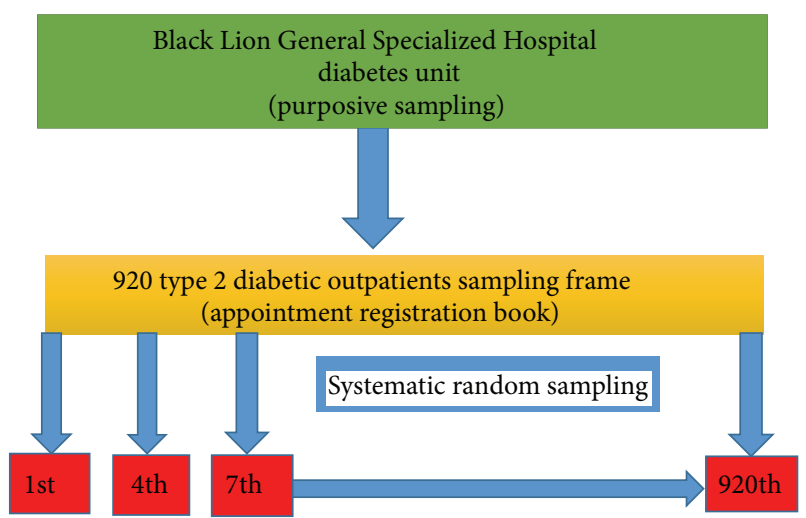

FIGURE 1: Schematic presentation of sampling procedure for the study in Black Lion General Specialized Hospital, Addis Ababa, Ethiopia, 2013.

from sampling frame developed by giving a number for all 920 patients in the registration book ascendingly. Since the sampling interval was 3 , a number between 1 and 3 was selected randomly by lottery method and number 1 was drawn first to take as a starting patient for the interview.

\subsection{Inclusion and Exclusion Criteria}

4.8.1. Inclusion Criteria. Patients were approached by the research team and invited to participate in the study that were as follows:

(i) diagnosed as type 2 diabetic patient based on laboratory result (blood sugar level) and clinical finding for at least one year,

(ii) age $\geq 20$ years old,

(iii) being capable of independent communication and giving informed verbal consent.

4.8.2. Exclusion Criteria. The exclusion criteria are as follows:

(i) Patients with type 1 diabetes mellitus.

(ii) Patients who were currently being treated for depression,

(iii) age $<20$ years old.

(iv) Not capable of independent communication.

(v) Patients who have refused to participate in the study.

4.9. Method of Data Collection. Quantitative and qualitative data was collected by using structured interviewer administered questionnaire. Demographic and health related information was collected from each patient and medical records using data abstraction form. Depression status of patients was ascertained at the time of recruitment. The Patient Health Questionnaire 9 (PHQ 9) was used to evaluate depression status of patients.

Patients with established type 2 diabetes mellitus were evaluated for depression by administering nine-item Patient 
Health Questionnaire 9 (PHQ 9) adapted from Pfizer Inc. using local language.

\subsection{Variable Specification}

4.10.1. Dependent Variables. Dependent variable is the response that is measured and it is the presumed effect. In this research the dependent variable is;

(i) Depression.

4.10.2. Independent Variables. Independent variable is the variable that is varied or manipulated by the researcher, and the presumed cause. In this research the independent variable is;

(i) Type 2 diabetes mellitus.

\subsection{Operational Definition}

(i) No depression: Patient Health Questionnaire 9 score is 0 .

(ii) Minimal depression: Patient Health Questionnaire 9 score is $1-4$.

(iii) Mild depression: Patient Health Questionnaire 9 score is $5-9$.

(iv) Moderate depression: Patient Health Questionnaire 9 score is $10-14$.

(v) Moderately severe depression: Patient Health Questionnaire 9 score is $15-19$.

(vi) Severe depression: Patient Health Questionnaire 9 score is $20-27$.

4.12. Data Processing and Analysis. After checking collected data visually for completeness, the response was coded and entered into the computer using EPI info version 3.5.1. Statistical packages, and then $10 \%$ of the responses was randomly selected and checked for the consistency of data entry. Then printed frequencies were used for checking of outliers and for cleaning data. Data was cleaned accordingly and then exported to SPSS version 20.0 (IBM SPSS Corp.) for further analysis. The frequency distribution of dependent and independent variables were worked out and presented in table, figure, and graph.

4.13. Data Quality Issues. To assure quality of the data, properly designed data collection tool was prepared and pretested and training was given to data collectors. Additionally, on each data collection day, the collected data was reviewed and checked for its completeness by principal investigator and appropriate design and sampling procedure was applied. Moreover, the exclusion criteria were considered.

4.14. Ethical Considerations. In order to follow the ethical and legal standards of scientific investigation, the study was conducted after approval of the proposal by Addis Ababa
University institutional review board. Participation was voluntary and information was collected anonymously after obtaining verbal consent from each respondent by assuring confidentiality throughout the data collection period.

\section{Result}

5.1. Sociodemographic Characteristics. Totally 264 type 2 diabetic outpatients were interviewed with a response rate of $95.6 \%$. As shown in Table 1, of whom those interviewed patients $53.0 \%$ (140) were female, 69.3\% (183) were married, $80.7 \%$ (213) were Orthodox Christian, and 57.2\% (151) were Amhara. In addition, the mean \pm SD age at diagnosis and current age of patients were $43.9 \pm 10.9$ and $55.9 \pm 10.9$ years, respectively. Besides, $86.4 \%$ (228) lived in Addis Ababa, and $61.7 \%$ (163) were with waist circumference of $\geq 95 \mathrm{~cm}$ (mean $\pm \mathrm{SD}, 98.9 \pm 11.1)$. Likewise, the median monthly income of the family was 750 ETB (651-1400 ETB) and 33.7\% (89) were attended college/university level education.

5.2. Clinical Characteristics. As illustrated in Table 2, $43.2 \%$ (145) of patients were on oral hypoglycemic treatment, 78.3\% (141) were with cardiovascular diseases (hypertension and heart failure), and $69.7 \%$ (140) were with diabetic retinopathy. Above and beyond, 58.7\% (155) of patients reported 1 to 2 comorbid disease (mean $\pm \mathrm{SD}, 1.1 \pm 0.9$ ) that is, evidenced by review of patient's medical record. Similarly, 50\% (132) were with $\mathrm{BMI} \leq 24.9 \mathrm{~kg} / \mathrm{m}^{2}$ (mean $\pm \mathrm{SD}, 25.4 \pm 3.7$ ) and reported physical disability. One hundred one $(38.3 \%)$ patients were living with diabetes mellitus for $\leq 8$ years and $25.0 \%$ (66) taking physician prescribed medication for $>17$ years (mean $\pm \mathrm{SD}, 12 \pm 7.9)$. Regarding the laboratory reported fasting blood glucose level, $12.9 \%$ (34) were with $\leq 100 \mathrm{mg} / \mathrm{dL}, 19.7 \%$ (52) were with $101-126 \mathrm{mg} / \mathrm{dL}$, and $67.4 \%$ (178) were with $\geq 127 \mathrm{mg} / \mathrm{dL}$.

5.3. Psychosocial Attributes. As depicted in Figure 2, 75.6\% (192) were reported that health care cost for type 2 diabetes treatment was high and 22\% (55) of patients do physical activity as recommended by the physician.

5.4. Reliability and Item Analysis. Cronbach's $\alpha$ for the PHQ9 scale was 0.72 indicating acceptable consistency of this psychometric scale for the study population. The correlations between nine items of the PHQ-9 and total PHQ-9 scores ranged from 0.22 to 0.69 , and all correlations were significant at the 0.01 level.

5.5. Prevalence of Depression. The mean $\pm \mathrm{SD}$ of $\mathrm{PHQ} 9$ score was $5.2 \pm 4.6$. Twenty five (9.5\%) type 2 diabetic outpatients did not report any of depressive symptoms. As showed in Figure 3, from the rest of 239 type 2 diabetic outpatients, $28.4 \%$ (75) fulfilled the criteria for mild depression, that is, PHQ 9 score 5-9, 12.1\% (32) for moderate depression, that is, PHQ 9 score $10-14,2.7 \%$ (7) for moderately severe depression, that is, PHQ 9 score $15-19$, and 1.5\% (4) for severe depression, that is, PHQ 9 score 20-27. But, $45.8 \%$ (121) of patients had no clinically significant depression. Since 
TABLE 1: Sociodemographic characteristics of type 2 diabetic outpatients in Black Lion General Specialized Hospital, Addis Ababa, Ethiopia, 2013. $(n=264)$.

\begin{tabular}{|c|c|c|c|}
\hline Variable & Category & $\begin{array}{l}\text { Frequency } \\
(n)\end{array}$ & $\begin{array}{c}\text { Percent } \\
(\%)\end{array}$ \\
\hline \multirow{2}{*}{ Sex } & Male & 124 & 47.0 \\
\hline & Female & 140 & 53.0 \\
\hline \multirow{2}{*}{ Residence } & Addis Ababa & 228 & 86.4 \\
\hline & $\begin{array}{c}\text { Outside Addis } \\
\text { Ababa }\end{array}$ & 36 & 13.6 \\
\hline \multirow{5}{*}{ Current age } & $<=49$ & 60 & 22.7 \\
\hline & $50-54$ & 53 & 20.1 \\
\hline & $55-59$ & 48 & 18.2 \\
\hline & $60-64$ & 43 & 16.3 \\
\hline & $>=65$ & 60 & 22.7 \\
\hline \multirow{6}{*}{ Age at diagnosis } & $<=34$ & 49 & 18.6 \\
\hline & $35-39$ & 45 & 17.0 \\
\hline & $40-44$ & 43 & 16.3 \\
\hline & $45-49$ & 49 & 18.6 \\
\hline & $50-54$ & 27 & 10.2 \\
\hline & $>=55$ & 51 & 19.3 \\
\hline \multirow{4}{*}{ Marital status } & Single & 9 & 3.4 \\
\hline & Married & 183 & 69.3 \\
\hline & Divorced & 24 & 9.1 \\
\hline & Widowed & 48 & 18.2 \\
\hline \multirow{5}{*}{ Religion } & Orthodox & 213 & 80.7 \\
\hline & Muslim & 24 & 9.1 \\
\hline & Protestant & 20 & 7.6 \\
\hline & Catholic & 2 & 0.8 \\
\hline & Others & 5 & 1.9 \\
\hline \multirow{5}{*}{ Ethnicity } & Amhara & 151 & 57.2 \\
\hline & Oromo & 40 & 15.2 \\
\hline & Tigre & 25 & 9.5 \\
\hline & Gurage & 29 & 11.0 \\
\hline & Others & 19 & 7.2 \\
\hline \multirow{5}{*}{ Educational status } & $\begin{array}{l}\text { Cannot read and } \\
\text { write }\end{array}$ & 35 & 13.3 \\
\hline & $\begin{array}{l}\text { Read and write } \\
\text { only }\end{array}$ & 16 & 6.1 \\
\hline & $\begin{array}{l}\text { Primary school } \\
\quad(1-8)\end{array}$ & 65 & 24.6 \\
\hline & Secondary (9-12) & 59 & 22.3 \\
\hline & College/University & 89 & 33.7 \\
\hline \multirow{8}{*}{ Occupation } & Farmer & 6 & 2.3 \\
\hline & Civil servant & 47 & 17.8 \\
\hline & Merchant & 10 & 3.8 \\
\hline & House wife & 47 & 17.8 \\
\hline & Private worker & 38 & 14.4 \\
\hline & Pensioned & 58 & 22.0 \\
\hline & No employment & 48 & 18.2 \\
\hline & Others & 10 & 3.8 \\
\hline
\end{tabular}

TABLE 1: Continued.

\begin{tabular}{lccc}
\hline Variable & Category & $\begin{array}{c}\text { Frequency } \\
(n)\end{array}$ & $\begin{array}{c}\text { Percent } \\
(\%)\end{array}$ \\
\hline Monthly family & $<=650$ & 125 & 47.3 \\
income (ETB) & $651-1400$ & 61 & 23.1 \\
& $>=1401$ & 78 & 29.5 \\
\hline Waist circumference & $<95$ & 101 & 38.3 \\
$(\mathrm{~cm})$ & $>=95$ & 163 & 61.7 \\
\hline
\end{tabular}

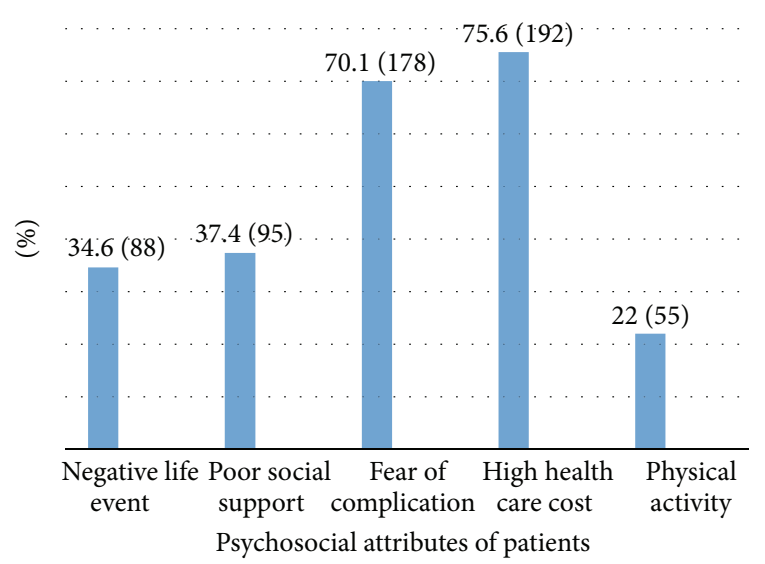

FIGURE 2: Distribution of psychosocial attributes among type 2 diabetic outpatients in Black Lion General Specialized Hospital, Addis Ababa, Ethiopia, 2013.

only 118 patients reported clinically significant depression, the overall prevalence rate of depression among type 2 diabetic outpatients was found 13\%. As depicted in Figure 4, 43.5\% (103) of patients express their feeling that the presence of depressive symptoms made "somewhat difficult" to do work, take care of things at home, or to get along with other people.

\section{Discussion}

It is difficult to accurately estimate the potential medical care needs and public health burdens of depression in the general diabetic population [23]. However, in spite of the huge impact of comorbid depression and diabetes on the individual and its importance as a public health problem, little is known about the existence of depression in people with diabetes in Ethiopia. This study has tried to address this issue.

The purpose of this study was to assess prevalence of comorbid depression in a random sample of outpatients with type 2 diabetes mellitus in Black Lion General Specialized Hospital, Addis Ababa, Ethiopia. To our knowledge, this study was the first that has investigated depression among type 2 diabetic outpatients using a PHQ 9 psychometric scale.

This study revealed that from 264 type 2 diabetic outpatients, $28.4 \%$ (75) fulfilled the criteria for mild depression, that is, PHQ 9 score 5-9, 12.1\% (32) for moderate depression, that is, PHQ 9 score $10-14,2.7 \%$ (7) for moderately severe depression, that is, PHQ 9 score $15-19$, and $1.5 \%$ (4) for severe depression, that is, PHQ 9 score 20-27. But, $45.8 \%$ (121) of patients had no clinically significant depression and $9.5 \%$ 
TABLE 2: Clinical characteristics of type 2 diabetic outpatients in Black Lion General Specialized Hospital, Addis Ababa, Ethiopia, 2013. $(n=264)$.

\begin{tabular}{|c|c|c|c|}
\hline Variable & Category & Frequency & $\begin{array}{c}\text { Percent } \\
(\%)\end{array}$ \\
\hline \multirow{4}{*}{$\begin{array}{l}\text { Diabetes treatment } \\
\text { regimen }\end{array}$} & Single insulin & 108 & 40.9 \\
\hline & Combined insulin & 12 & 4.5 \\
\hline & $\begin{array}{l}\text { Insulin plus oral } \\
\text { hypoglycemic }\end{array}$ & 30 & 11.4 \\
\hline & Oral hypoglycemic & 114 & 43.2 \\
\hline \multirow{3}{*}{$\begin{array}{l}\text { Duration of diabetes } \\
\text { (years) }\end{array}$} & $<=8$ & 101 & 38.3 \\
\hline & $9-16$ & 96 & 36.4 \\
\hline & $17+$ & 67 & 25.4 \\
\hline \multirow{3}{*}{$\begin{array}{l}\text { Duration of diabetes } \\
\text { treatment (years) }\end{array}$} & $<=8$ & 105 & 39.8 \\
\hline & $9-16$ & 93 & 35.2 \\
\hline & $17+$ & 66 & 25.0 \\
\hline \multirow{5}{*}{ Comorbid disease $^{\mathrm{a}}$} & $\begin{array}{c}\text { Cardiovascular } \\
\text { disease }\end{array}$ & 141 & $78.3 \%$ \\
\hline & Respiratory disease & 17 & $9.4 \%$ \\
\hline & Renal disease & 13 & $7.2 \%$ \\
\hline & Neurologic disease & 4 & $2.2 \%$ \\
\hline & $\begin{array}{c}\text { Other comorbid } \\
\text { disease }\end{array}$ & 80 & $44.4 \%$ \\
\hline \multirow{4}{*}{$\begin{array}{l}\text { Complication of } \\
\text { diabetes }^{b}\end{array}$} & $\begin{array}{l}\text { Diabetic } \\
\text { retinopathy }\end{array}$ & 140 & $69.7 \%$ \\
\hline & $\begin{array}{c}\text { Diabetic } \\
\text { nephropathy }\end{array}$ & 69 & $34.3 \%$ \\
\hline & $\begin{array}{c}\text { Diabetic } \\
\text { neuropathy }\end{array}$ & 83 & $41.3 \%$ \\
\hline & Sexual dysfunction & 69 & $34.3 \%$ \\
\hline \multirow{3}{*}{ Body mass index } & $<=24.9$ & 132 & 50.0 \\
\hline & $25.0-29.9$ & 98 & 37.1 \\
\hline & $>=30$ & 34 & 12.9 \\
\hline \multirow{3}{*}{ Fasting blood glucose } & $<=100$ & 34 & 12.9 \\
\hline & $101-126$ & 52 & 19.7 \\
\hline & $>=127$ & 178 & 67.4 \\
\hline \multirow{3}{*}{$\begin{array}{l}\text { Number of } \\
\text { comorbidities }\end{array}$} & 0 & 83 & 31.4 \\
\hline & $1-2$ & 155 & 58.7 \\
\hline & $>=3$ & 26 & 9.8 \\
\hline \multirow{3}{*}{$\begin{array}{l}\text { Number of prescribed } \\
\text { medication } \\
\text { administrations per day }\end{array}$} & $<=4$ & 77 & 29.2 \\
\hline & $5-6$ & 113 & 42.8 \\
\hline & $7+$ & 74 & 28.0 \\
\hline \multirow{3}{*}{$\begin{array}{l}\text { Number of diabetic } \\
\text { complications }\end{array}$} & 0 & 65 & 24.6 \\
\hline & $1-2$ & 148 & 56.1 \\
\hline & $>=3$ & 51 & 19.3 \\
\hline \multirow{2}{*}{ Physical disability } & Yes & 132 & 50.0 \\
\hline & No & 132 & 50.0 \\
\hline \multirow{2}{*}{ Medication burden } & $\leq 3$ & 77 & 29.2 \\
\hline & $\geq 4$ & 187 & 70.8 \\
\hline
\end{tabular}

a: number of respondents is 180 and b: number of respondents is 201 .

(25) of patients did not report any of depressive symptoms. When a cut-off score of PHQ $9 \geq 10$ (i.e. moderate to severe depression) was used, the prevalence was $18 \%$ (43). However,

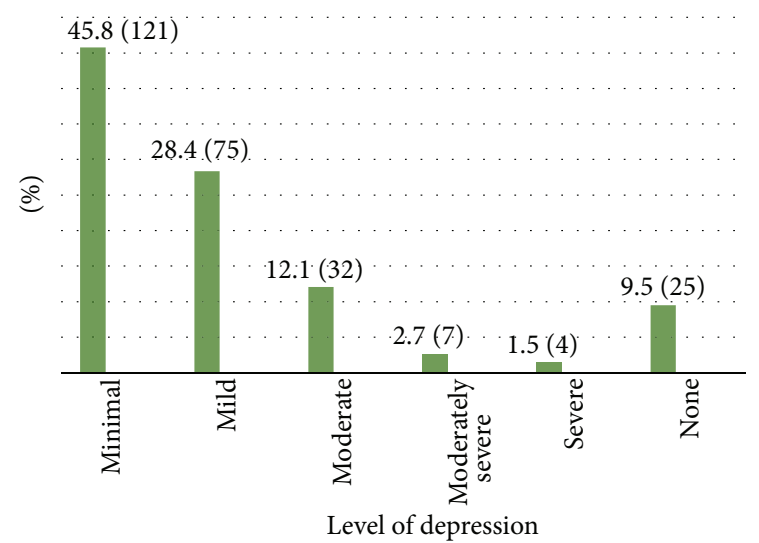

FIgURE 3: The prevalence of comorbid depression based on PHQ 9 score among type 2 diabetic outpatients in Black Lion General Specialized Hospital, Addis Ababa, Ethiopia, 2013.

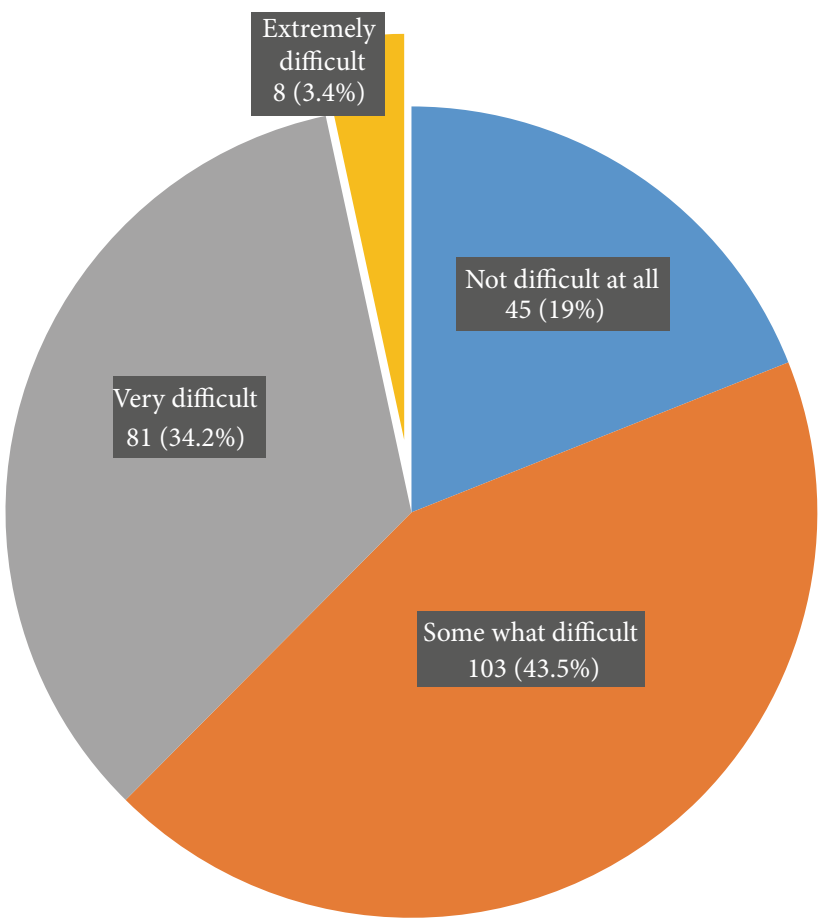

FIGURE 4: Level of difficulty of depressive symptoms among type 2 diabetic outpatients to do their work, take care of things at home, or get along with other people in Black Lion General Specialized Hospital, Addis Ababa, Ethiopia, 2013.

the prevalence of depression was $49.4 \%$ (118) when a cut-off score of PHQ $9 \geq 5$ was used.

This finding was comparable with the result from a crosssectional study done in Bangladesh using PHQ 9 psychometric tool, depicted that the prevalence of depressive symptoms using PHQ-9 (score $\geq 5$ ) was 34\% (142). When a cut-off value (PHQ-9 $\geq 10$ ) indicative of moderate to severe depression was used, the prevalence was to be $16.5 \%$ (69) [25].

On the other hand this finding was relatively lower than a cross-sectional study conducted in Chandigarh, India; 
discovered that from 300 type 2 diabetic patients, 23\% (68) fulfilled the criteria for severe depression, $18 \%$ (54) for moderate depression and 59\% (178) had no clinically significant depression [2]. This discrepancy might be due to variation in sample size.

From the total of 920 type 2 diabetic outpatient candidates, only 118 patients reported clinically significant depression. Therefore, the overall prevalence rate of depression among type 2 diabetic outpatients was found $13 \%$. This finding was smaller than the finding of a cross-sectional study at Jos University Teaching Hospital, Jos, Nigeria that discovered the prevalence rate of depression among diabetic outpatients was $19.4 \%$ [27], a small study from Iran that reported 55\% prevalence of depression in patients with type 2 diabetic patients [26] and a study done in Mexico, the prevalence of depression, diagnosed using the Beck Depression Inventory, was found to be $46 \%$ in patients with Type 2 diabetes [ 15 , 22 ]. Correspondingly, it was lower by half from the review report by McIntyre et al. who showed that the prevalence of depressive symptoms has been found to be $27 \%$ in type 2 diabetes mellitus [8].

These discrepancies of prevalence might be due to variation in attributes of study participants, use of different psychometric scale, study design, setting, time frame, and the level of country development.

Providing the patients with the results of blood sugar, cholesterol, blood pressure, and medications plan through outpatient service is not enough itself to improve service delivery and bring about change [25]. The findings of this study have major implications for clinical practice in the Black Lion General Specialized Hospital and other health care settings in the country, where clinicians' recognition of mental disorder rates is low and improving recognition rates is a challenge because of high patient loads and poor undergraduate training in these skills.

\section{Strength and Limitation}

The strengths of this study include a high response rate and the inclusive nature of this research as individuals could participate regardless of literacy level. Additionally, rather than having to rely on self-report, health related information was collected from patients' medical records. Also, a reasonable sample size and ascertaining depression with culturally standardized questionnaires are strengths of this study. At last, since it was the first study in type, it will provide basic information for those who are interested.

However, an important limitation of this study was that Patient Health Questionnaire 9 psychiatric scale was used which was not the gold standard method to assess depression. Likewise there was absence of similar study done in Ethiopia health care setting to compare the finding during discussion.

\section{Conclusion}

In conclusion, this study demonstrated that depression is a common comorbid health problem in type 2 diabetic outpatients in Black Lion General Specialized Hospital, Ethiopia.
Within this sample of outpatients with type 2 diabetes mellitus, the study found that the prevalence rate of depression was $13 \%$.

This study provides rich data on the prevalence of depression in type 2 diabetic outpatients in Ethiopia. In a setting where recognition, screening, and treatment levels remain low, health care providers need to focus their efforts on diagnosing, referring and effectively treating comorbid depression in order to deliver rights-based and client-centered services for people in real needs.

\section{List of Acronyms and Abbreviations}

BMI: Body mass index

CAD: Coronary artery diseases

CI: Confidence interval

DSM: Diagnostic statistical manual of mental disorders

EDID: European depression in diabetes

E.g.: Example

et al.: Et alia

ETB: Ethiopian birr

FBS: $\quad$ Fasting blood sugar

FDRE: Federal Democratic Republic of Ethiopia

FMOH: Federal ministry of health

IBM: International business machine

$\mathrm{Kg} / \mathrm{m}^{2}$ : Kilogram per meter square

MDD: Major depressive disorder

MOH: Ministry of Health

NGOs: Nongovernmental Organizations

PHQ: Patient Health Questionnaire

SD: $\quad$ Standard deviation

SPSS: Statistical package for social science

T2DM: Type 2 diabetes mellitus

UK: United Kingdom

USA: United States of America

Vs.: Versus.

\section{Disclosure}

Yosef Tsige Radie and Nigussie Tadesse Sharew are coauthors.

\section{Conflict of Interests}

The authors declare that there is no conflict of interests regarding the publication of this research paper.

\section{Acknowledgments}

The authors' in-depth gratitude goes to the Addis Ababa University for giving this chance and financial support too. The authors would like to thank Dr. Yewondweson Tadesse, Department Head of Internal Medicine; Dr. Tedilla Kebede, Physicians Coordinator in diabetes clinic; Sr. Abeba Mulugeta, Nurses Coordinator in diabetes clinic; and officials in the Black Lion General Specialized Hospital for their collaboration to permit and facilitate data collection. Supervisors, data collectors, and respondents were highly 
acknowledged for investing their precious time in supervising, collecting data, and providing the necessary information. They would like to offer their great respect and appreciation to all their friends and senior instructors who gave them precious time for advice and comments during data entry and analysis.

\section{References}

[1] Z. Roupa, A. Koulouri, P. Sotiropoulou et al., "Anxiety and depression in patients with Type 2 Diabetes Mellitus, depending on sex and body mass index," Health Science Journal, vol. 3, no. 1, pp. 32-40, 2009.

[2] A. Raval, E. Dhanaraj, A. Bhansali, S. Grover, and P. Tiwari, "Prevalence \& determinants of depression in type 2 diabetes patients in a tertiary care centre," Indian Journal of Medical Research, vol. 132, no. 8, pp. 195-200, 2010.

[3] International Diabetes Federation, Diabetes Atlas, 5th edition, 2012, http://www.indiaenvironmentportal.org.in/files/file/ diabetes\%20atlas\%202012.pdf.

[4] D. L. Musselman, E. Betan, H. Larsen, and L. S. Phillips, "Relationship of depression to diabetes types 1 and 2: epidemiology, biology, and treatment," Biological Psychiatry, vol. 54, no. 3, pp. 317-329, 2003.

[5] S. Perveen, M. S. Otho, M. N. Siddiqi, J. Hatcher, and G. Rafique, "Association of depression with newly diagnosed type 2 diabetes among adults aged between 25 to 60 years in Karachi, Pakistan," Diabetology and Metabolic Syndrome, vol. 2, no. 1, article 17, 2010.

[6] G. A. Nichols and J. B. Brown, "Unadjusted and adjusted prevalence of diagnosed depression in type 2 diabetes," Diabetes Care, vol. 26, no. 3, pp. 744-749, 2003.

[7] P. Reddy, B. Philpot, D. Ford, and J. A. Dunbar, "Identification of depression in diabetes: the efficacy of PHQ-9 and HADS-D," British Journal of General Practice, vol. 60, no. 575, pp. e239e245, 2010.

[8] R. S. McIntyre, D. A. Mancini, M. M. Pearce et al., "Mood and psychotic disorders and type 2 diabetes: a metabolic triad," Canadian Journal of Diabetes, vol. 29, no. 2, pp. 122-132, 2005.

[9] M. de Groot, M. Kushnick, T. Doyle et al., "Depression among adults with diabetes: prevalence, impact, and treatment options," Diabetes Spectrum, vol. 23, no. 1, pp. 15-18, 2010.

[10] H. R. Bogner, K. H. Morales, H. F. de Vries, and A. R. Cappola, "Integrated management of type 2 diabetes mellitus and depression treatment to improve medication adherence: a randomized controlled trial," Annals of Family Medicine, vol. 10, no. 1, pp. 15-22, 2012.

[11] D. M. Naranjo, L. Fisher, P. A. Areán, D. Hessler, and J. Mullan, "Patients with type 2 diabetes at risk for major depressive disorder over time," Annals of Family Medicine, vol. 9, no. 2, pp. 115-120, 2011.

[12] L. E. Egede and D. Zheng, "Independent factors associated with major depressive disorder in a national sample of individuals with diabetes," Diabetes Care, vol. 26, no. 1, pp. 104-111, 2003.

[13] T. P. Gilmer, C. Walker, E. D. Johnson, A. Philis-Tsimikas, and J. Unützer, "Improving treatment of depression among latinos with diabetes using project dulce and IMPACT," Diabetes Care, vol. 31, no. 7, pp. 1324-1326, 2008.

[14] C. M. van der Feltz-Cornelis, "Depression in diabetes mellitus: to screen or not to screen? A patient-centred approach," British
Journal of Diabetes and Vascular Disease, vol. 11, no. 6, pp. 276$281,2011$.

[15] "Foot care basics," Diabetes Resources: Practical Information for New Mexico Health Care Professionals, vol. 15, no. 6, 2011.

[16] S. Asghar, A. Hussain, S. M. K. Ali, A. K. A. Khan, and A. Magnusson, "Prevalence of depression and diabetes: a populationbased study from rural Bangladesh," Diabetic Medicine, vol. 24, no. 8, pp. 872-877, 2007.

[17] K. Ell, W. Katon, L. J. Cabassa et al., "Depression and diabetes among low-income hispanics: design elements of a socioculturally adapted collaborative care model randomized controlled trial," International Journal of Psychiatry in Medicine, vol. 39, no. 2, pp. 113-132, 2009.

[18] P. J. O’Connor, A. L. Crain, W. A. Rush, A. M. Hanson, L. R. Fischer, and J. C. Kluznik, "Does diabetes double the risk of depression?” Annals of Family Medicine, vol. 7, no. 4, pp. 328335, 2009.

[19] C. Li, E. S. Ford, T. W. Strine, and A. H. Mokdad, "Prevalence of depression among U.S. adults with diabetes: findings from the 2006 behavioral risk factor surveillance system," Diabetes Care, vol. 31, no. 1, pp. 105-107, 2008.

[20] R. D. Goldney, P. J. Phillips, L. J. Fisher, and D. H. Wilson, "Diabetes, depression, and quality of life: a population study," Diabetes Care, vol. 27, no. 5, pp. 1066-1070, 2004.

[21] T. Kendrick, C. Dowrick, A. McBride et al., "Management of depression in UK general practice in relation to scores on depression severity questionnaires: analysis of medical record data," British Medical Journal, vol. 338, no. 7697, article 750, 2009.

[22] N. Zahid, S. Asghar, B. Claussen, and A. Hussain, "Depression and diabetes in a rural community in Pakistan," Diabetes Research and Clinical Practice, vol. 79, no. 1, pp. 124-127, 2008.

[23] A. M. Acee, "Detecting and managing depression in type II diabetes: PHQ-9 is the answer!," Medsurg Nursing, vol. 19, no. 1, pp. 32-38, 2010.

[24] F. Pouwer, P. H. L. M. Geelhoed-Duijvestijn, C. J. Tack et al., "Prevalence of comorbid depression is high in out-patients with Type 1 or Type 2 diabetes mellitus. Results from three outpatient clinics in the Netherlands," Diabetic Medicine, vol. 27, no. 2, pp. 217-224, 2010.

[25] T. Roy, C. E. Lloyd, M. Parvin, K. G. B. Mohiuddin, and M. Rahman, "Prevalence of co-morbid depression in out-patients with type 2 diabetes mellitus in Bangladesh," BMC Psychiatry, vol. 12, article 123, 2012.

[26] M. E. Khamseh, H. R. Baradaran, and H. Rajabali, "Depression and diabetes in Iranian patients: a comparative study," International Journal of Psychiatry in Medicine, vol. 37, no. 1, pp. 81-86, 2007.

[27] T. M. Agbir, M. D. Audu, T. O. Adebowale, and S. G. Goar, "Depression among medical outpatients with diabetes: a crosssectional study at Jos University Teaching Hospital, Jos, Nigeria," Annals of African Medicine, vol. 9, no. 1, pp. 5-10, 2010.

[28] S. Hailemariam, F. Tessema, M. Asefa, H. Tadesse, and G. Tenkolu, "The prevalence of depression and associated factors in Ethiopia: findings from the National Health Survey," International Journal of Mental Health Systems, vol. 6, article 23, 2012.

[29] N. Hermanns and B. Kulzer, "Diabetes and depression-a burdensome Co-morbidity: a report," European Endocrinology, vol. 4, no. 2, pp. 19-22, 2008.

[30] Toronto Addis Ababa Academic Collaboration: Black Lion Hospital, http://www.missbdesign.com/clients/TAAAC/about_ BlackLionHospital.html. 


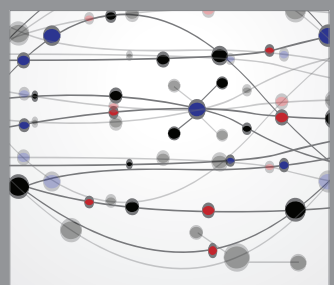

The Scientific World Journal
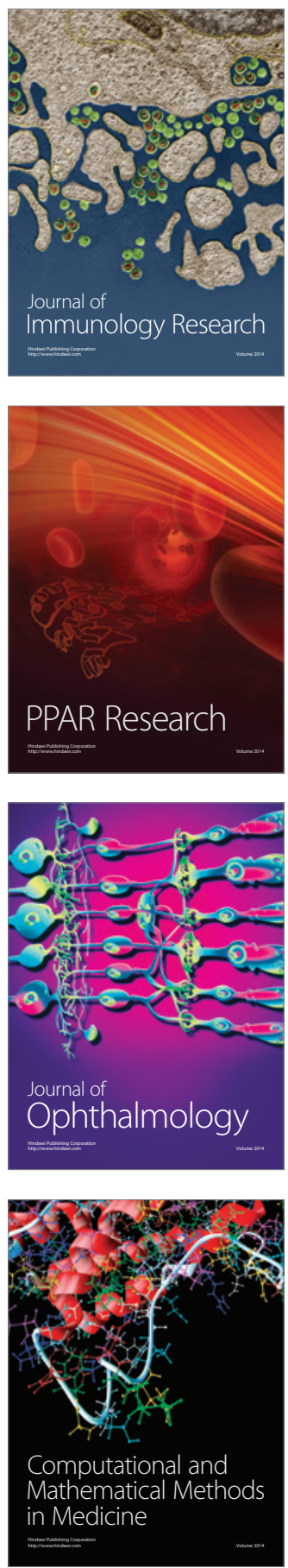

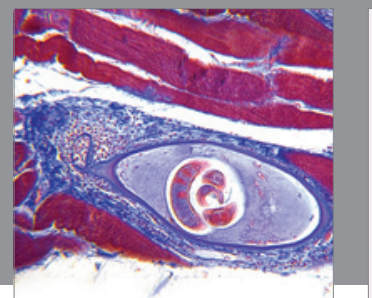

Gastroenterology

Research and Practice
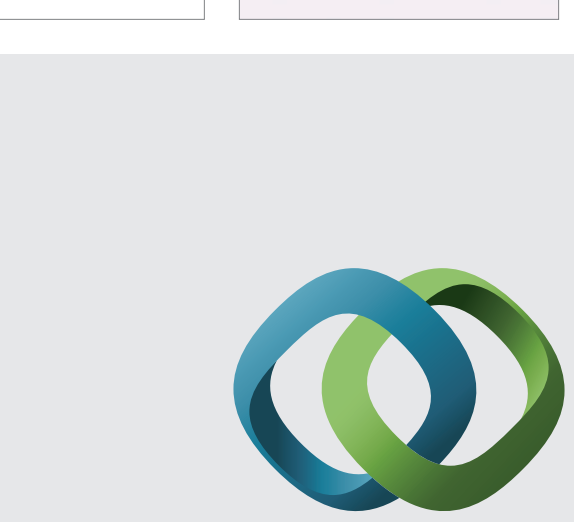

\section{Hindawi}

Submit your manuscripts at

http://www.hindawi.com
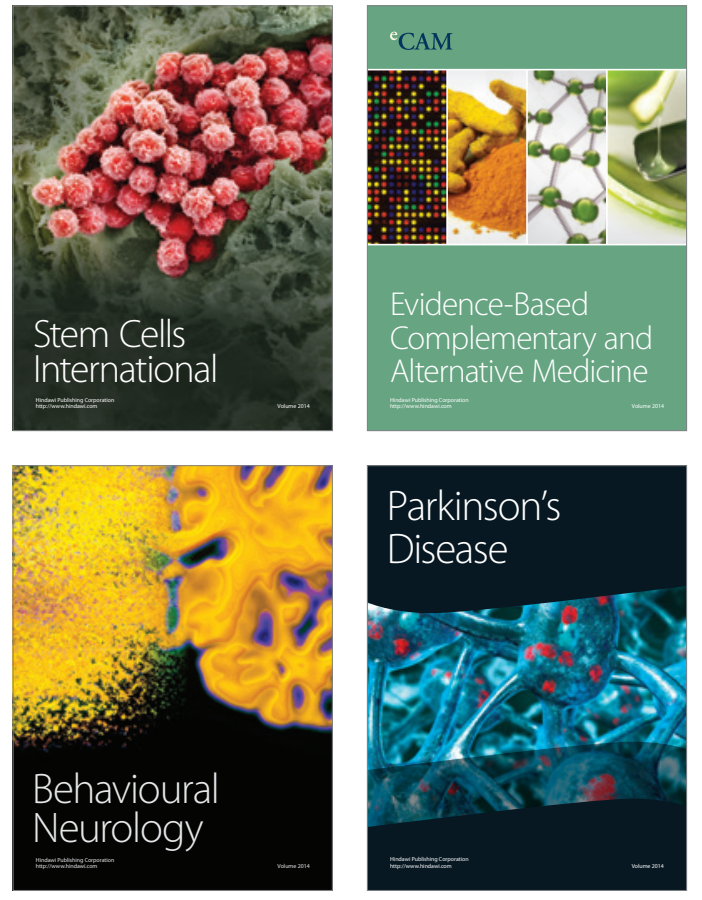
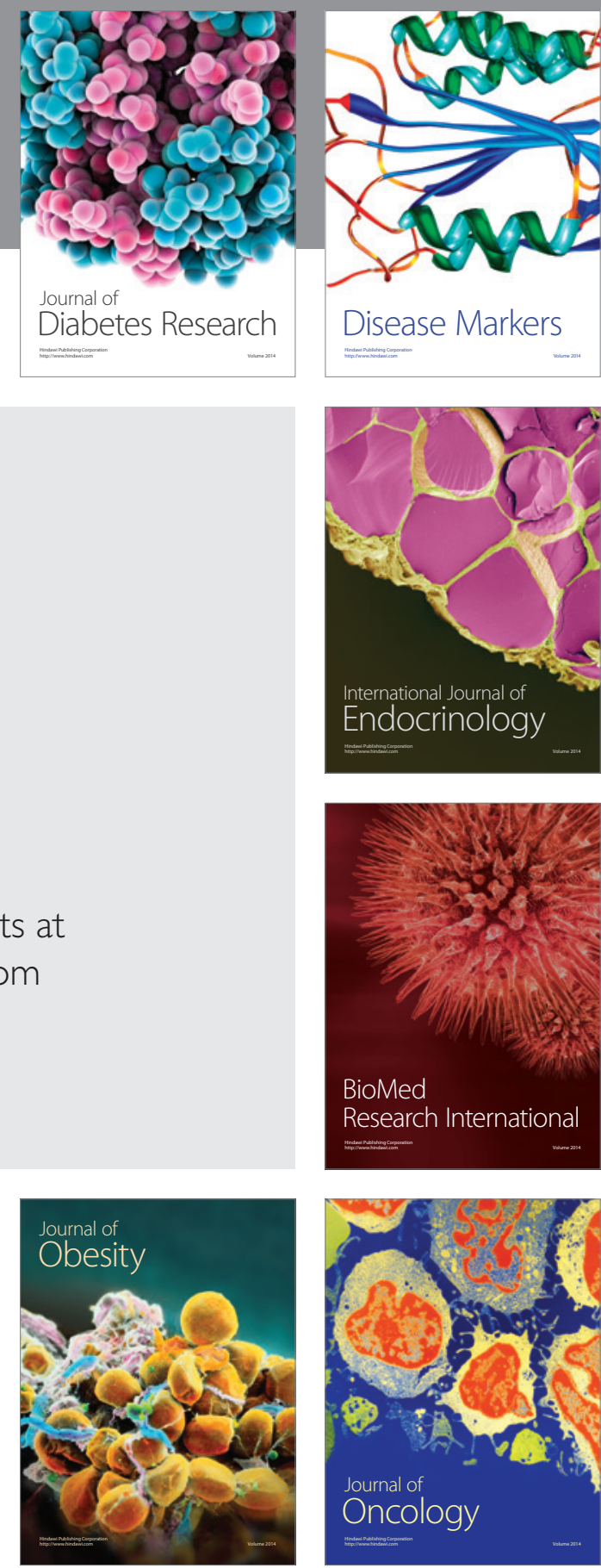

Disease Markers
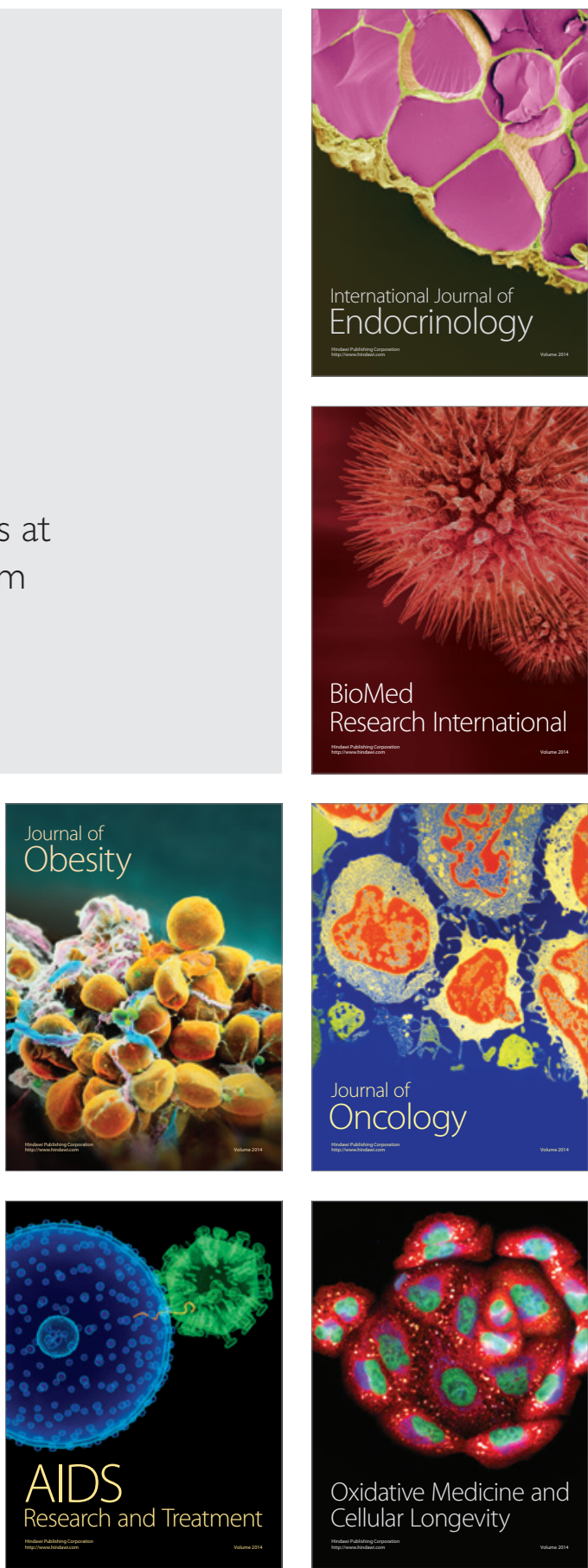